\title{
Molecular Electrostatic Potential Devices on Graphite and Silicon Surfaces
}

\author{
Norma L. Rangel and Jorge M. Seminario* \\ Department of Chemical Engineering \\ Department of Electrical and Computer Engineering \\ Texas A\&M University \\ College Station, TX 77843-3122
}

\section{SUPPLEMENTARY INFORMATION}

For the sake of completeness we have include all not shown and shown surfaces from Figures 3, 5,6 , and 7 from the manuscript.

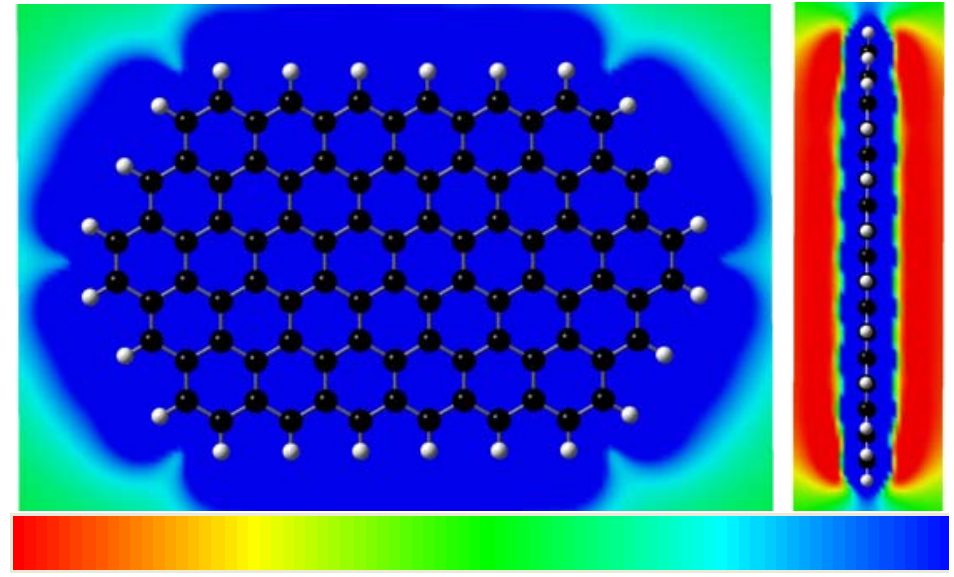

(a)
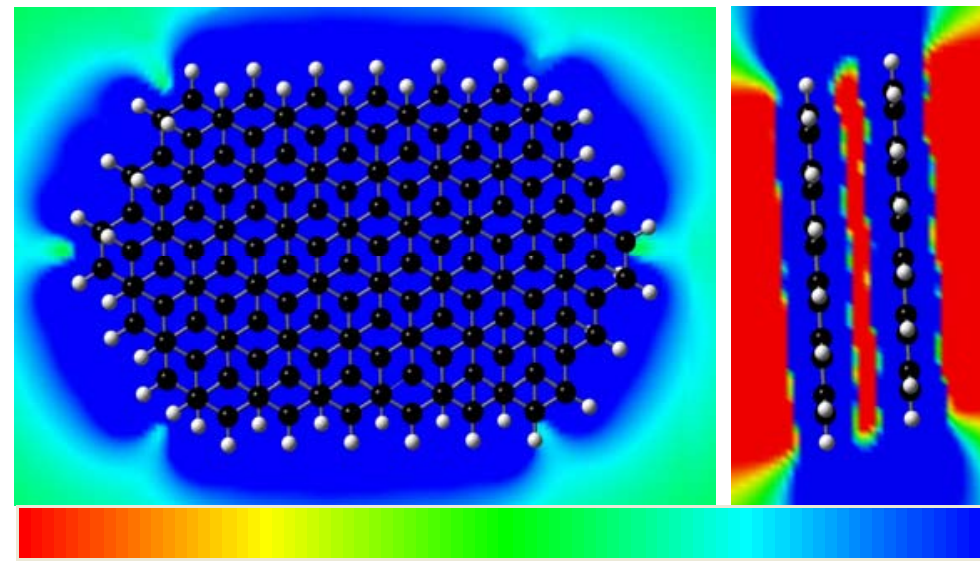

(b) 


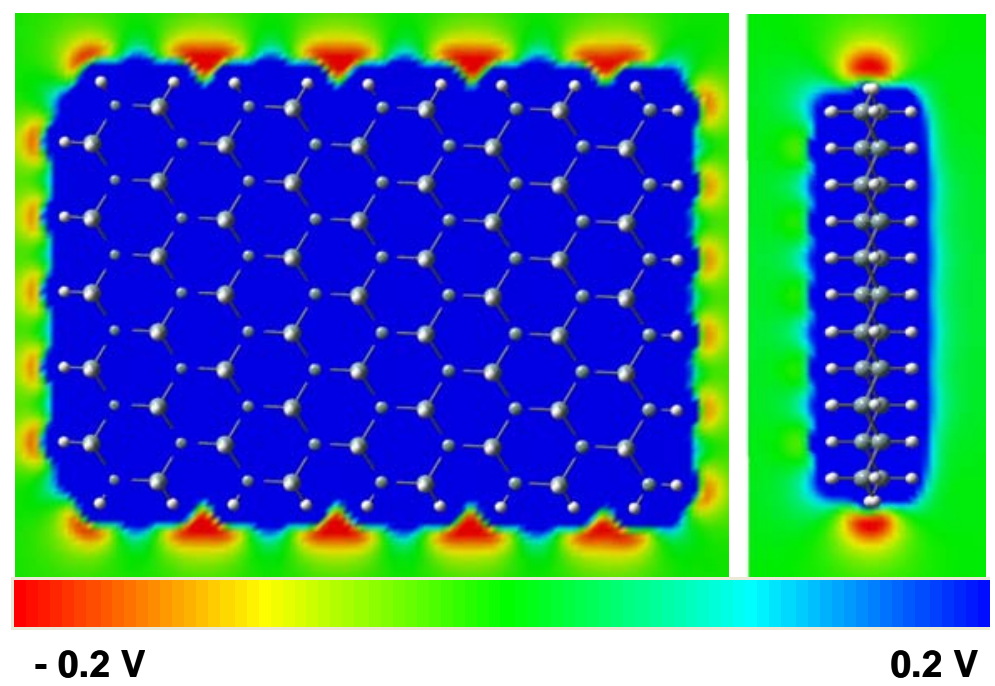

(c)

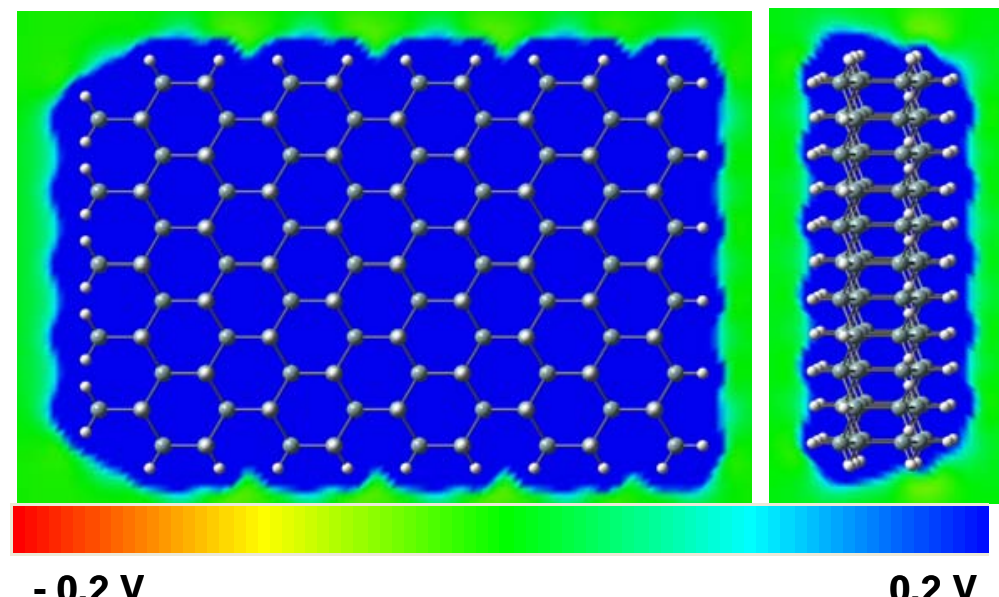

(d)

Figure 3X. The MEP of the graphene used as the substrate. a) one layer, b) two layers. The MEP for hydrogen passivated silicon used as a substrate c) one layer, and d) two layers. As a reference for the size, the C-H bonds are 1.07, C-C 1.42, Si-H 1.47, and Si-Si 2.34.
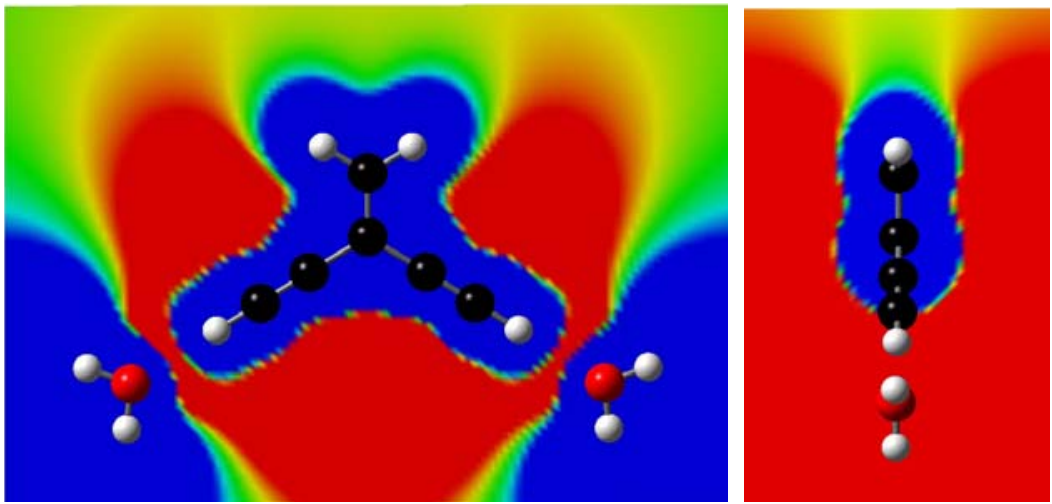


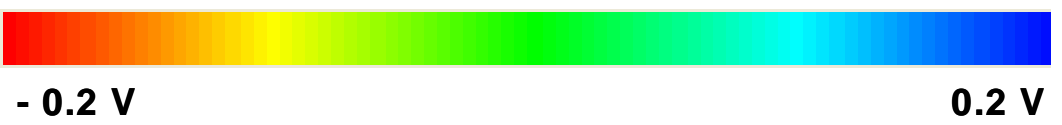

(a)

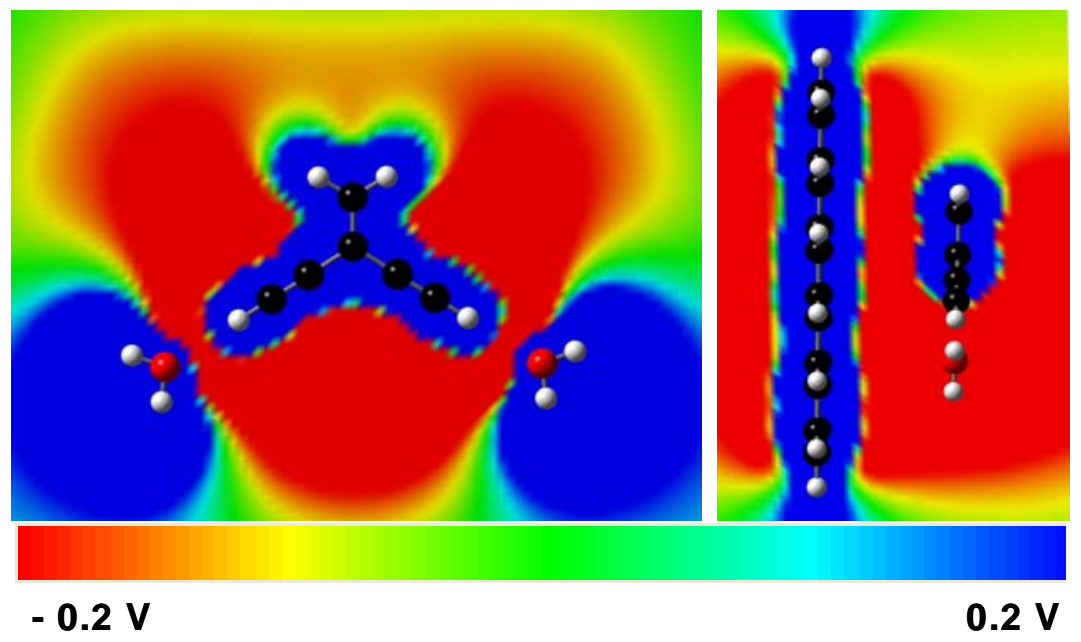

(b)

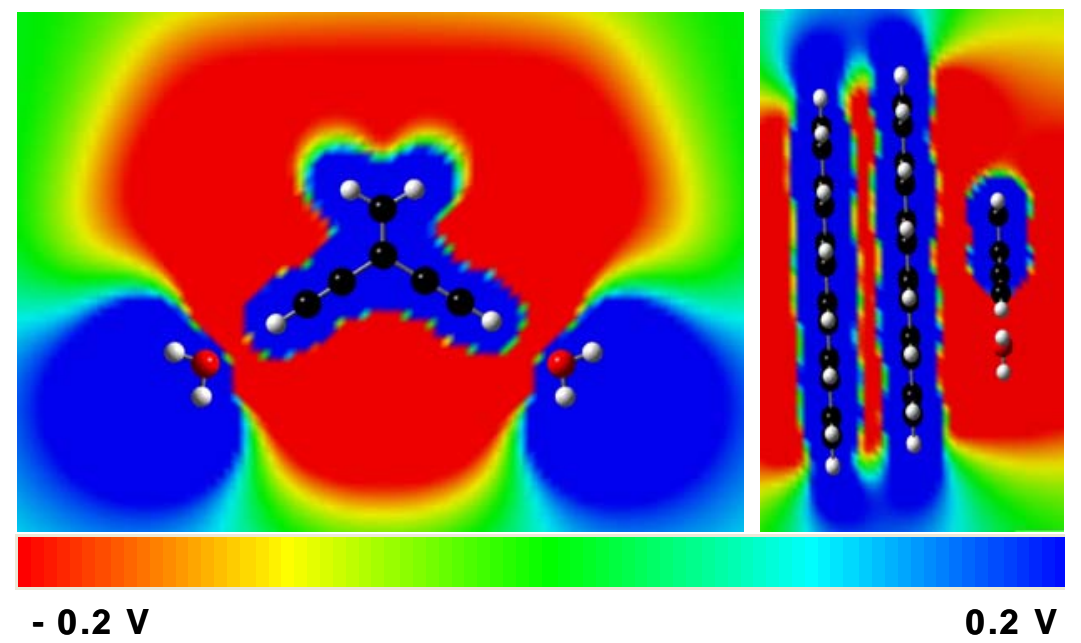

(c) 

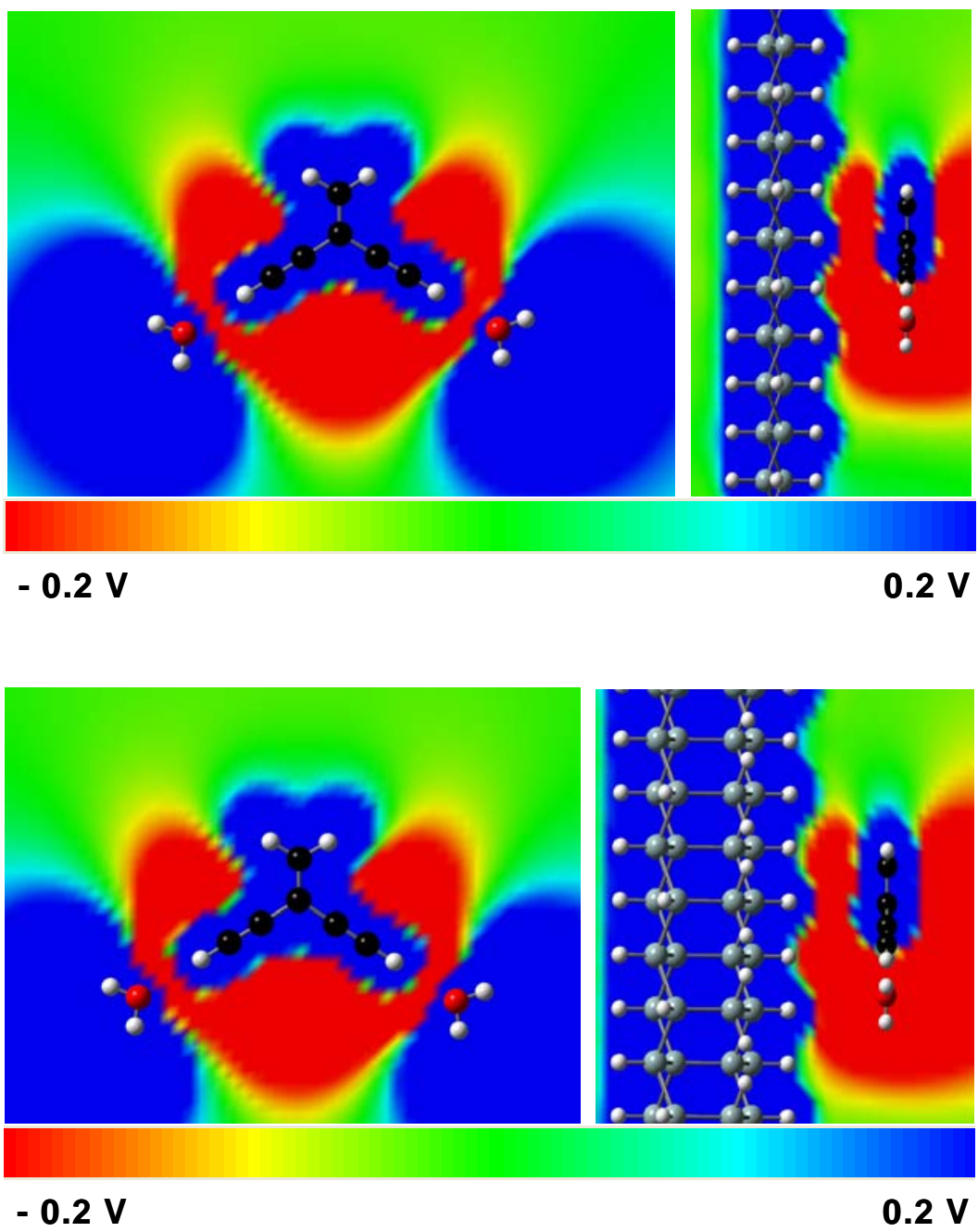

(c)

Figure 5X. Molecular electrostatic potentials for (a) the isolated molecular gate in vacuum and over substrates of (b) one graphene layer and (c) two graphene layers, as well as of (c) one H-passivated silicon layer and (e) two Hpassivated silicon layers when the two inputs to the gate are negative.
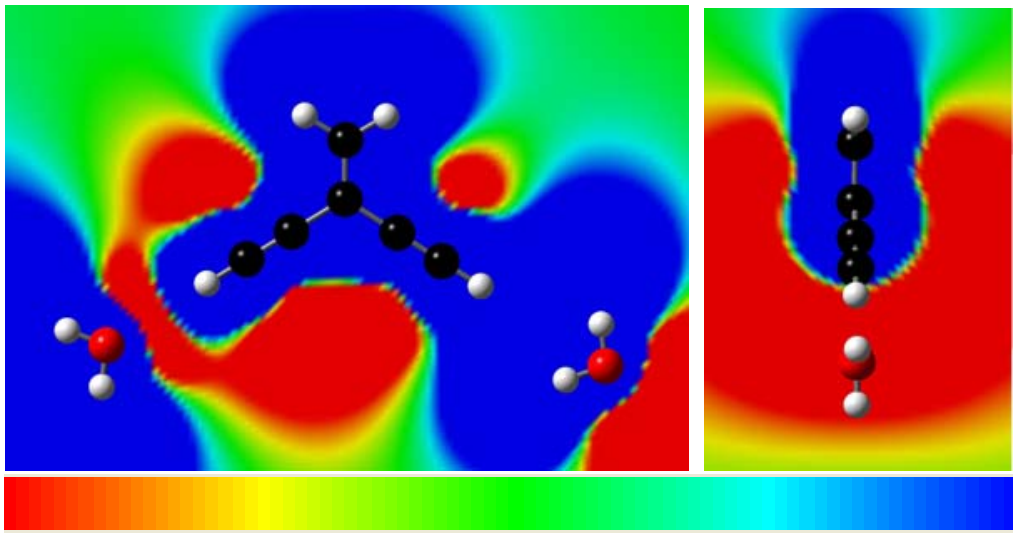

(a) 


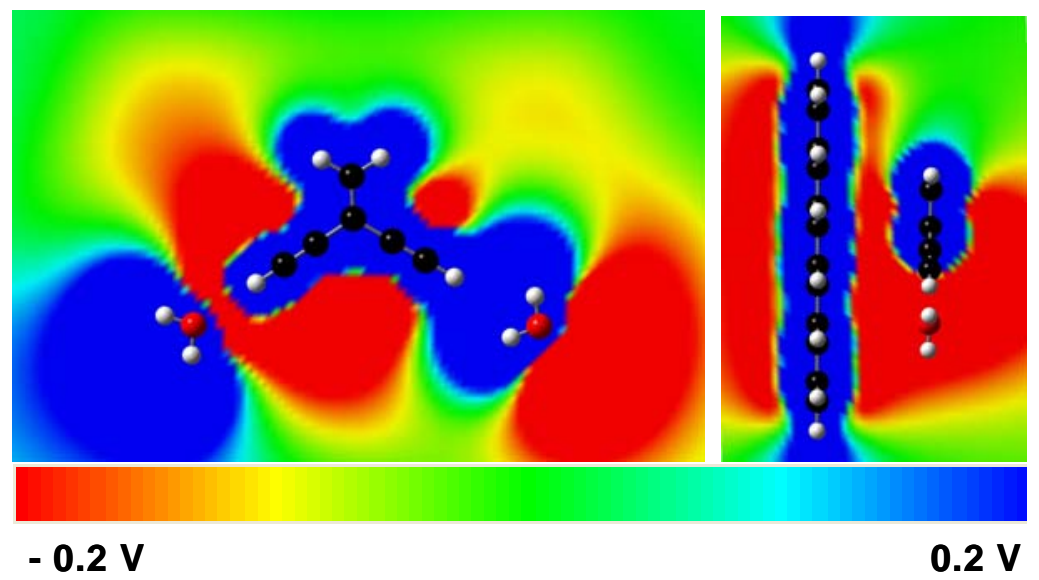

(b)

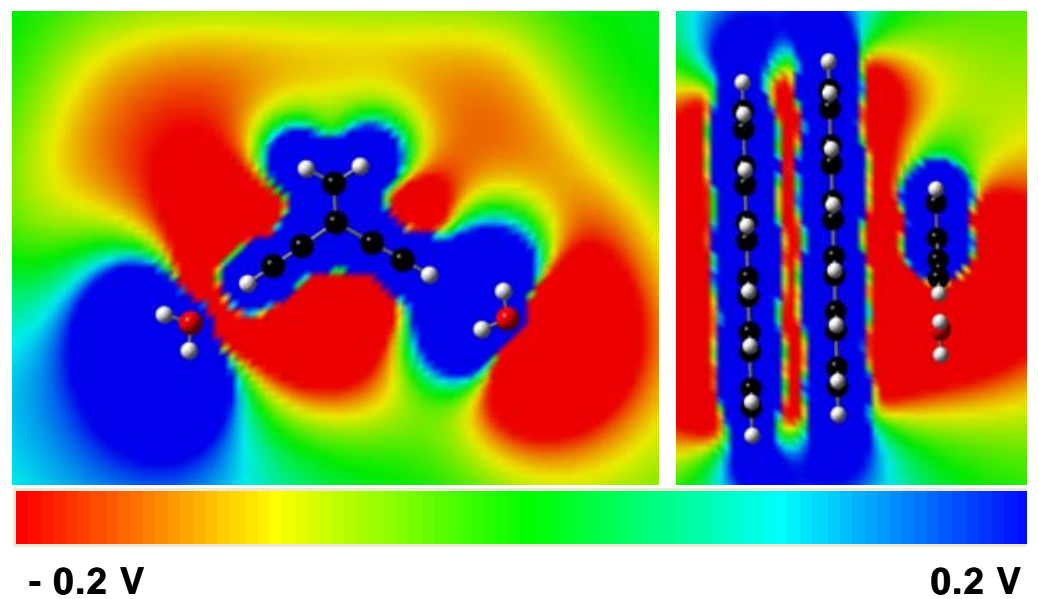

(c)
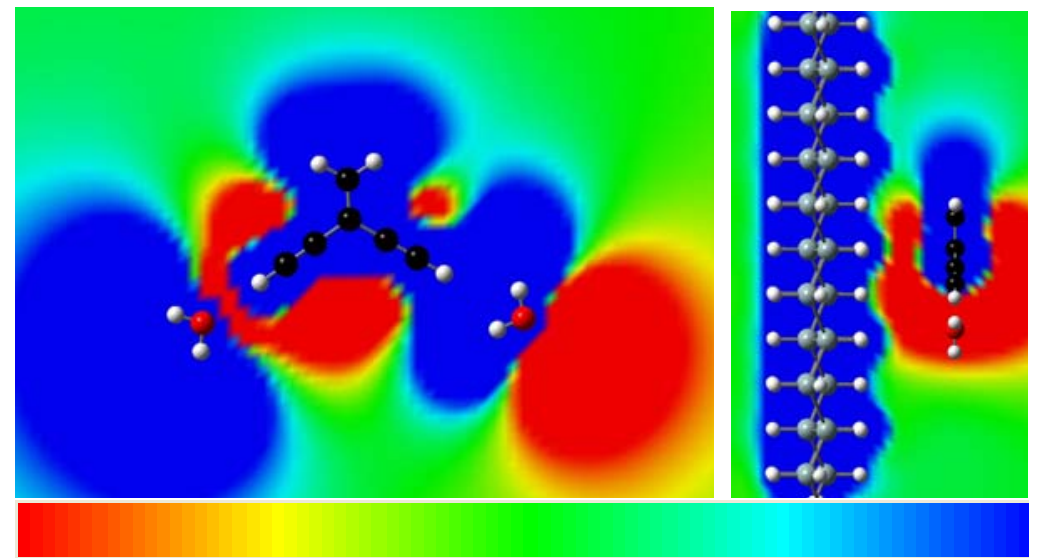

-0.2 V

$0.2 \mathrm{~V}$

(d) 

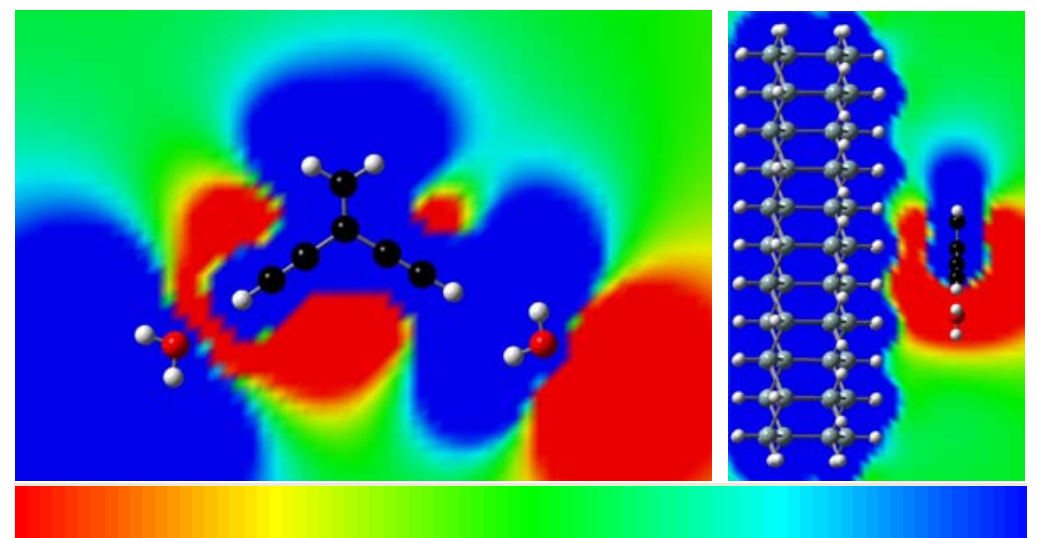

\section{$-0.2 \mathrm{~V}$}

$0.2 \mathrm{~V}$

(e)

Figure 6X. Molecular electrostatic potentials for (a) the isolated molecular gate in vacuum and over substrates of (b) one graphene layer and (c) two graphene layers, as well as of (c) one H-passivated silicon layer and (e) two $\mathrm{H}$ passivated silicon layers when one input is negative and the other is positive.

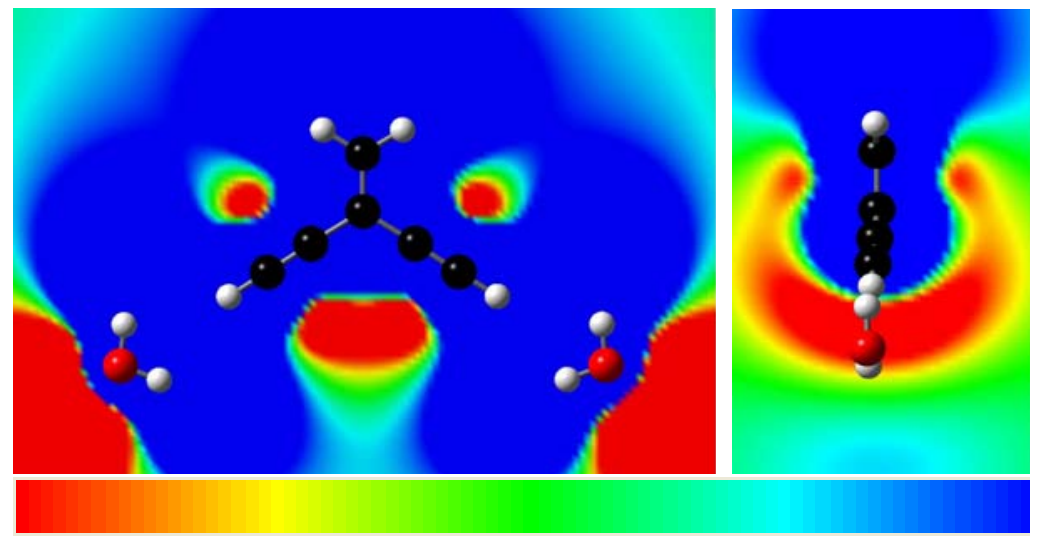

$-0.2 \mathrm{~V}$

(a)
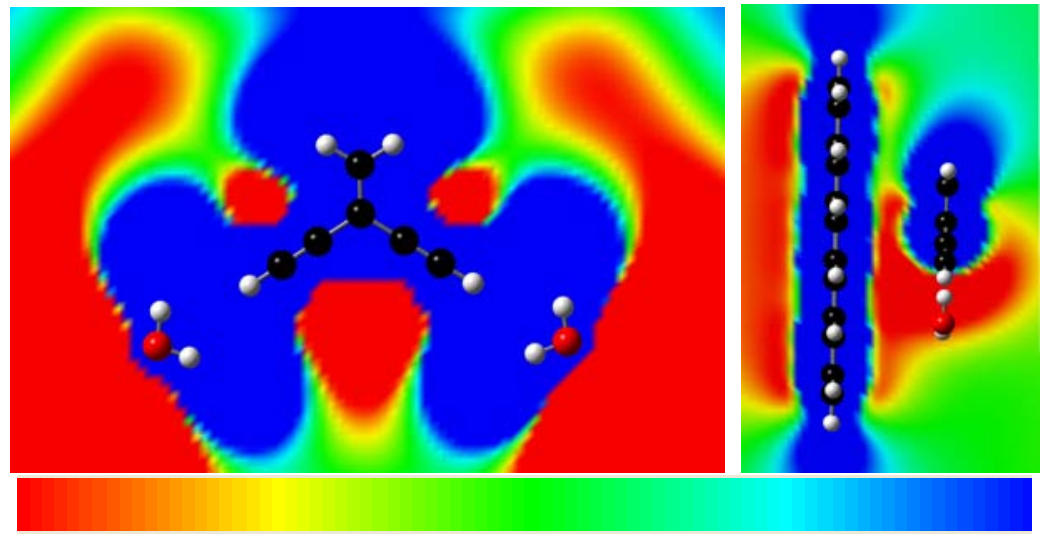

-0.2 V

$0.2 \mathrm{~V}$

(b) 


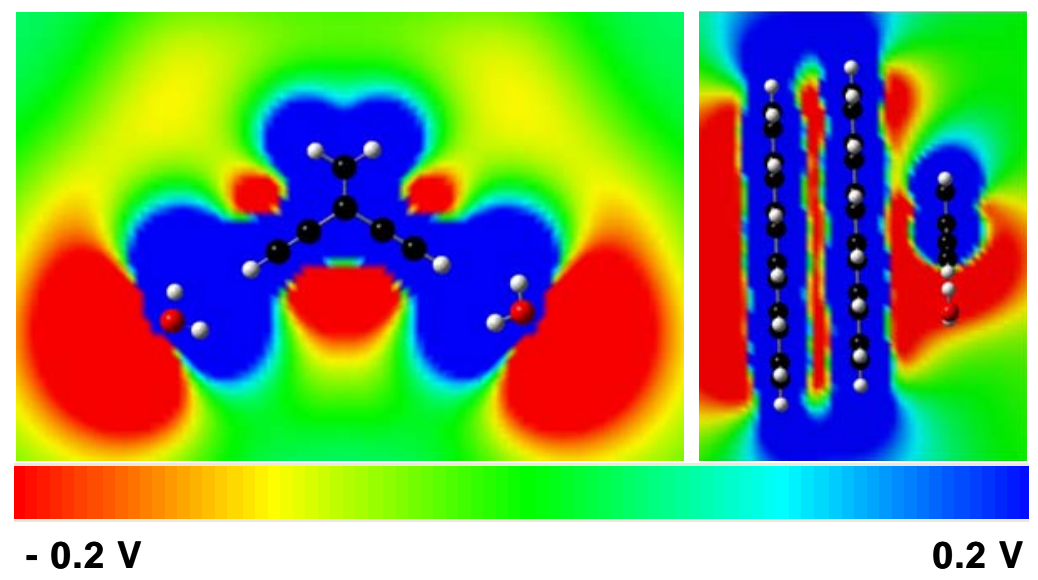

(c)
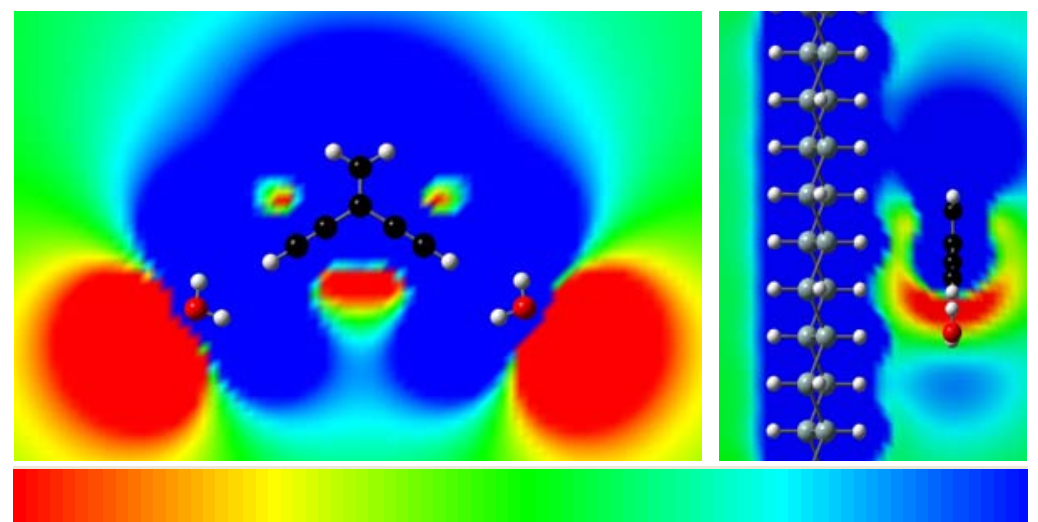

$-0.2 \mathrm{~V}$

$0.2 \mathrm{~V}$

(d)
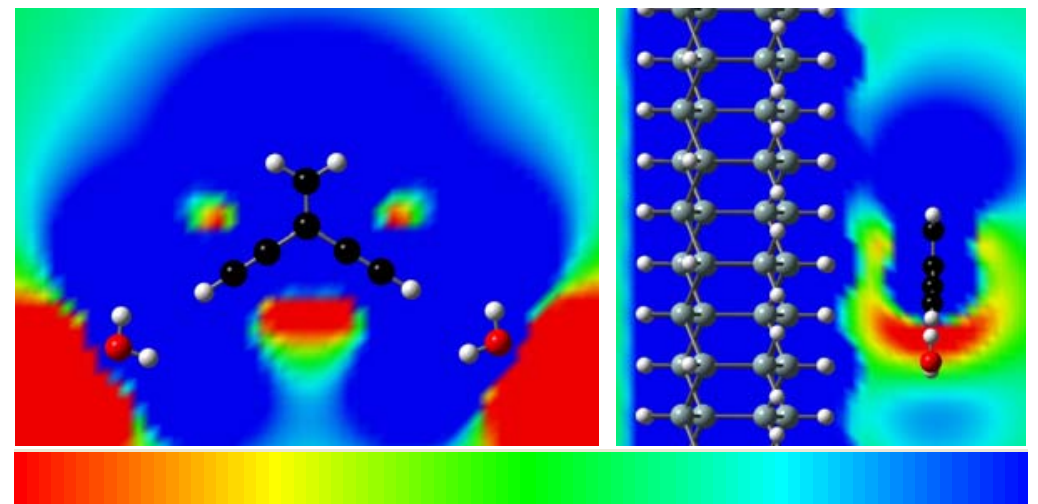

$-0.2 \mathrm{~V}$

$0.2 \mathrm{~V}$

(e)

Figure 7X. Molecular electrostatic potentials for (a) the isolated molecular gate in vacuum and over substrates of (b) graphite, and (c) hydrogen-passivated silicon when the two inputs to the gate are positive. 
Table 1. Truth tables for the MEP gate with and without substrates

\begin{tabular}{|c|c|c|c|c|c|c|c|c|c|}
\hline \multicolumn{2}{|c|}{ Potentials } & \multicolumn{2}{|c|}{ Logical } & \multirow{2}{*}{ Isolated } & \multirow{2}{*}{$\begin{array}{c}\text { one small } \\
\text { sheet of } \\
\text { graphene }\end{array}$} & \multirow{2}{*}{$\begin{array}{l}\text { one sheet } \\
\text { graphene }\end{array}$} & \multirow{2}{*}{$\begin{array}{c}\text { two } \\
\text { sheets } \\
\text { graphene }\end{array}$} & \multirow{2}{*}{$\begin{array}{l}\text { one sheet } \\
\text { of silicon }\end{array}$} & \multirow{2}{*}{$\begin{array}{c}\text { two } \\
\text { sheets of } \\
\text { silicon } \\
\end{array}$} \\
\hline A & $\mathrm{B}$ & A & B & & & & & & \\
\hline- & - & 0 & 0 & 0 & 0 & 0 & 0 & 0 & 0 \\
\hline- & + & 0 & 1 & 1 & 0 & 0 & 0 & 1 & 1 \\
\hline+ & - & 1 & 0 & 1 & 0 & 0 & 0 & 1 & 1 \\
\hline \multirow[t]{2}{*}{+} & + & 1 & 1 & 1 & 0 & 1 & 1 & 1 & 1 \\
\hline & & & & OR & $\mathbf{0}$ & AND & AND & OR & OR \\
\hline
\end{tabular}

